\title{
Hydrothermal Synthesis of Sodium and Potassium Niobates Fine Particles and Their Application to Lead-Free Piezoelectric Material
}

\author{
Kiyoshi Kanie ${ }^{1, *}$, Yoshiki Numamoto ${ }^{1,2}$, Shintaro Tsukamoto ${ }^{2}$, \\ Hirofumi Takahashi ${ }^{2}$, Hideto Mizutani ${ }^{3}$, Atsuki Terabe ${ }^{3}$, \\ Masafumi Nakaya ${ }^{1}$, Junji Tani ${ }^{1}$ and Atsushi Muramatsu ${ }^{1}$ \\ ${ }^{1}$ Institute of Multidisciplinary Research for Advanced Materials, Tohoku University, Sendai 980-8577, Japan \\ ${ }^{2}$ Fuji Ceramics Corporation, Fujinomiya 418-0111, Japan \\ ${ }^{3}$ Sakai Chemical Industry Co. Ltd., Iwaki 971-8183, Japan
}

Cubic-shaped potassium and sodium niobates fine particles with orthorhombic crystal structures were successfully obtained by two-step hydrothermal reaction at $100^{\circ} \mathrm{C}$ for $24 \mathrm{~h}$ and $150-250^{\circ} \mathrm{C}$ for $3 \mathrm{~h}$ using a highly concentrated $\mathrm{KOH}$ or $\mathrm{NaOH}$ aqueous solution and a niobium pentachloride aqueous solution. The particle mean sizes were gradually controlled by changing the initial $\mathrm{KOH}$ and $\mathrm{NaOH}$ concentrations. Preheating of the precursor solution at $100^{\circ} \mathrm{C}$ for $24 \mathrm{~h}$ played an important role to obtain the desired alkali metal niobates fine particles with flat and smooth surfaces. The present potassium niobate fine particles exhibited good sintering property keeping with the original particle size and shape. Furthermore, thus obtained KN ceramics showed high piezoelectric properties. [doi:10.2320/matertrans.M2011148]

(Received May 18, 2011; Accepted August 11, 2011; Published September 28, 2011)

Keywords: perovskite, sodium niobate, potassium niobate, fine particle, hydrothermal synthesis, piezoelectricity, lead free

\section{Introduction}

Alkaline metal niobates have attracted great deal of attention as a future functional material because of their excellent ferroelectric, piezoelectric, electro-optic, nonlinear optical, photorefractive, photocatalytic, and ion conductive properties. $^{1-10)}$ Especially, potassium niobate with a perovskite-type structure is regarded as one of the most promising piezoelectric materials as a substitute for the lead zirconate titanate (PZT). PZT is extensively used as high performance piezoelectric ceramics; however, large lead content in the PZT-based products evoked serious problems. ${ }^{11-13)}$ In spite of its hazardous characteristics, PZT is exempted from the Restriction of the Use of Certain Hazardous Substances regulation ${ }^{14}$ ) (RoHS: a law enacted in the European Union to limit the amount of hazardous elements in a product) because suitable alternatives have not yet been specified. Meanwhile, since extensive researches have been progressed to improve piezoelectric performance and Curie temperature of potassium niobate-based ceramics, great potentials as PZT alternatives have been clarified. ${ }^{2,6,7,15)}$ In general, such potassium niobates are presently synthesized by a conventional solidstate reaction of potassium carbonates and niobium pentoxide $\left(\mathrm{Nb}_{2} \mathrm{O}_{5}\right)$ at temperatures of more than $800^{\circ} \mathrm{C}$. Because potassium oxide starts to volatilize at $900^{\circ} \mathrm{C},{ }^{16)}$ the prolonged and high temperature reaction lead to undesired change in the stoichiometry, reduction in the density, and degradation in the performance.

In contrast, hydrothermal synthesis has large potentials to obtain highly purified and homogenized metal oxide powders controlled in their stoichiometry, size, crystalline diameter, and morphology. ${ }^{17,18)}$ Recently, utilization of such welldefined metal oxide powders as precursors for piezoelectric ceramics has received much attention, because high performance ceramics close to a morphotropic phase boundary have

*Corresponding author, E-mail: kanie@tagen.tohoku.ac.jp been obtained by texture-treatment ${ }^{19)}$ or template grain growth method ${ }^{20)}$ using them. In our previous studies, we have developed preparation technique of shape-controlled bismuth sodium titanate $(\mathrm{BNT})^{21,22)}$ and bismuth potassium titanate $(\mathrm{BKT})^{22)}$ fine particles with complex perovskite-type structures from aqueous solutions. Since BNT and BKT, one of the most promising alternatives to PZT, their fine particles controlled in their size and shape, such as sphere, cube, rod, and nano-tube are readily prepared by the Gel-Sol method. ${ }^{17,23-30)}$

In previous studies on hydrothermal synthesis, potassium niobate $\left(\mathrm{KNbO}_{3}: \mathrm{KN}\right)$ and sodium niobate $\left(\mathrm{NaNbO}_{3}: \mathrm{NN}\right)$ powders have been successfully obtained by using $\mathrm{Nb}_{2} \mathrm{O}_{5}$ solid precursor and aqueous potassium hydroxide $(\mathrm{KOH})$ or sodium hydroxide $(\mathrm{NaOH}) .{ }^{31-35)}$ Furthermore, and sodium potassium niobates $\left(\mathrm{Na}_{x} \mathrm{~K}_{1-x} \mathrm{NbO}_{3}\right.$ : NKN) have also been obtained using $\mathrm{Nb}_{2} \mathrm{O}_{5}{ }^{36-40)}$ or $\mathrm{NbCl}_{5} \cdot{ }^{41)}$ However, in spite of the extensive efforts, precise control of $\mathrm{NN}$ and $\mathrm{KN}$ in their size and shape have never been achieved so far, highly coagulated and irregular-shaped $\mathrm{KN}$ and $\mathrm{NN}$ powders have only been prepared, expect for some interesting examples. ${ }^{5,32)}$ As mentioned above, $\mathrm{Nb}_{2} \mathrm{O}_{5}$ is used for $\mathrm{KN}$ and $\mathrm{NN}$ synthesis. $\mathrm{Nb}_{2} \mathrm{O}_{5}$ is one of the most accessible and cheap niobium sources, however, usage of $\mathrm{Nb}_{2} \mathrm{O}_{5}$ powder raises an inhomogeneous state because of its low solubility ${ }^{42}$ and advantage of hydrothermal synthesis are not fully utilized in the previous systems. In this regard, we have investigated synthesis of $\mathrm{KN}$ and $\mathrm{NN}$ fine particles using niobium pentachloride $\left(\mathrm{NbCl}_{5}\right)$ aqueous solution as a soluble precursor and developed an efficient procedure for the predominant preparation of $\mathrm{KN}$ and $\mathrm{NN}$ fine particles. We have also investigated effects of hydroxide concentration and preheating of the precursor solution on the shape, size, and polymorphism of the resulting $\mathrm{KN}$ and $\mathrm{NN}$ fine particles. Piezoelectric properties of KN and NKN ceramics prepared by using $\mathrm{KN}$ and $\mathrm{NN}$ fine particles obtained by the present procedure are also investigated. 


\section{Experimental}

$\mathrm{NbCl}_{5}$ (Cat. No: 141-03941), $\mathrm{NaOH}$ (granularity: Cat. No: 198-13765), $8.0 \mathrm{~mol} \cdot \mathrm{dm}^{-3} \mathrm{NaOH}$ aqueous solution (Cat. No: 194-09575), KOH (granularity: Cat. No: 168-21815), and $8.0 \mathrm{~mol} \cdot \mathrm{dm}^{-3} \mathrm{KOH}$ aqueous solution (Cat. No: 169-20365) were purchased from Wako Pure Chemicals Inc. and used asreceived.

An aqueous stock solution of $\mathrm{NbCl}_{5}$ was prepared as follows. $\mathrm{NbCl}_{5}(27.0 \mathrm{~g}, 0.100 \mathrm{~mol})$ was added to $0.10 \mathrm{~mol} / \mathrm{L}$ $\mathrm{HCl}$ aqueous solution $(180 \mathrm{~mL})$ in a screw-capped Pyrex bottle with agitation at $0^{\circ} \mathrm{C}$ to continue magnetically stirring for at least 3 days until the solid was totally dissolved. Total volume of the resulting transparent solution was adjusted to $200 \mathrm{~mL}$ at room temperature by further addition of $0.10 \mathrm{~mol} / \mathrm{L} \mathrm{HCl}$. Thus obtained aqueous solution was filtered through $0.2 \mu \mathrm{m}$ milli-pore filter to remove insoluble particulates. The resulting $0.50 \mathrm{~mol} / \mathrm{L} \mathrm{NbCl}_{5}$ in $\mathrm{HCl}$ aqueous solution was kept in a refrigerator.

The representative procedure for the preparation of $\mathrm{KN}$ fine particles in $18 \mathrm{~mol} \cdot \mathrm{dm}^{-3} \mathrm{KOH}$ was as follows. Initially, $0.50 \mathrm{~mol} \cdot \mathrm{dm}^{-3} \mathrm{NbCl}_{5}$ in $0.10 \mathrm{~mol} \cdot \mathrm{dm}^{-3} \mathrm{HCl}$ aqueous solution $(6.0 \mathrm{~mL})$ was added to a mixture of $16 \mathrm{~mol} \cdot \mathrm{dm}^{-3} \mathrm{KOH}$ aqueous solution $(1.36 \mathrm{~mL})$ and granular $\mathrm{KOH}(10.7 \mathrm{~g}$, $0.191 \mathrm{~mol}$ ) in a Teflon-made vessel at room temperature with stirring over $5 \mathrm{~min}$. Then, the total volume was adjusted to $12 \mathrm{~mL}$ by the addition of water, and the resulting suspensions were further stirred for $10 \mathrm{~min}$ at room temperature. The concentrations of $\mathrm{Nb}^{5+}$ and $\mathrm{K}^{+}$in the mixture were 0.25 and $18.0 \mathrm{~mol} \cdot \mathrm{dm}^{-3}$, respectively. Then the resulting suspension was placed into a Teflon-lined autoclave (Parr Instrument Company, 4749) and aged at $100^{\circ} \mathrm{C}$ for $24 \mathrm{~h}$ with stirring at $30 \mathrm{rpm}$ in an oven made by HIRO COMPANY. Then, the temperature of the oven was increased to $250^{\circ} \mathrm{C}$ over $1 \mathrm{~h}$, and aged at the temperature for $3 \mathrm{~h}$ with stirring. Obtained product was collected by centrifugation $(18,000 \mathrm{rpm}, 15 \mathrm{~min})$, and the sediments were washed with water $(20 \mathrm{~mL} \times 3$ times), by dispersing followed by centrifuging. The resulting precipitates were dried at $60^{\circ} \mathrm{C}$ in an oven for 1 day to obtain $\mathrm{KN}$ fine particles.

To investigate the effect of the $\mathrm{KOH}$ concentration, the initial $\mathrm{KOH}$ concentration was changed in the range from 2.0 to $18 \mathrm{~mol} \cdot \mathrm{dm}^{-3}$. By the similar procedure, NN fine particles were also prepared by adjusting the initial concentration from 2.0 to $20 \mathrm{~mol} \cdot \mathrm{dm}^{-3}$ using $8.0 \mathrm{~mol} \cdot \mathrm{dm}^{-3} \mathrm{NaOH}$ aqueous solution and granular $\mathrm{NaOH}$.

X-ray diffraction (XRD) measurements were carried out on a Rigaku Ultima-IV system using $\mathrm{CuK} \alpha$ radiation $(40 \mathrm{kV}$, $40 \mathrm{~mA}$ ) equipped with a D/teX Ultra detector. Field emission-scanning electron microscope (FE-SEM) images were taken by using a Hitachi S-4800 system with an acceleration voltage of $20 \mathrm{kV}$. The average particle sizes of the KN fine particles were calculated by counting 100 particles taken by the FE-SEM observations.

For the evaluation of piezoelectric properties of $\mathrm{KN}$ and NKN fine particles, the KN and NKN-based ceramics were prepared as follows. Hydrothermally prepared $\mathrm{KN}$ and $\mathrm{NN}$ powders were mixed with polyvinyl alcohol and pressed into discs of $7 \mathrm{~mm}$ in diameter and $0.8 \mathrm{~mm}$ in thickness. The resulting discs were calcined at $700^{\circ} \mathrm{C}$ for $4 \mathrm{~h}$ and sintered in the range from 1,020 to $1,060^{\circ} \mathrm{C}$ for $2 \mathrm{~h}$. Thus obtained $\mathrm{KN}$ and NKN ceramics were cut and polished to obtain discs of $6 \mathrm{~mm}$ in diameter and $0.4 \mathrm{~mm}$ in thickness for various physical and electrical measurements. Density of the polished ceramics was calculated by measuring the weight and the volume of the disks. Silver paste was used as the electrode for the detection of the dielectric properties of the resulting ceramics. The piezoelectric properties were measured by a HP/Agilent impedance analyzer HP4294A and a piezoelectric $d_{33}$ meter. The specimens for the piezoelectric measurements were polled in a stirred silicone bath at $100^{\circ} \mathrm{C}$ by applying a DC electrical field of $4 \mathrm{kV} / \mathrm{mm}$ for $10 \mathrm{~min}$.

\section{Results and Discussion}

\subsection{Effect of $\mathrm{KOH}$ concentration on formation of potassium niobate fine particles}

In the hydrothermal system to obtain metal oxide fine particles, hydroxide ion concentration is a critical rule on crystal structure and size of solid particles as well as their formation rate. ${ }^{17,43)}$ Actually, our previous studies obtaining complex perovskite fine particles such as BNT showed that initial $\mathrm{pH}$ strongly influenced to the crystal structure and shape of the particles. ${ }^{21,22)}$ In this regard, the effect of initial $\mathrm{KOH}$ concentrations was investigated on the formation rate and the morphology of $\mathrm{KN}$ fine particle. Here, the hydrothermal synthesis was carried out by following two-step aging: $100^{\circ} \mathrm{C}$ for $24 \mathrm{~h}$ and $250^{\circ} \mathrm{C}$ for $3 \mathrm{~h}$. The two-step aging process is an efficient procedure for the preparation of monodispersed fine particles in the Gel-Sol method. ${ }^{17)}$ The initial concentration of $\mathrm{Nb}^{5+}$ was fixed to $0.25 \mathrm{~mol} \cdot \mathrm{dm}^{-3}$, and the $\mathrm{KOH}$ concentration was adjusted from 2.0 to $18 \mathrm{~mol} \cdot \mathrm{dm}^{-3}$. For $2.0,4.0$, and $6.0 \mathrm{~mol} \cdot \mathrm{dm}^{-3}$, no solid precipitate was found after centrifugation of the two-step aged mixtures. In the $\mathrm{KOH}$ concentration range, niobium ions were dissolved in the $\mathrm{KOH}$ solution by formation of soluble complex such as potassium hexaniobate hydrate: $\mathrm{K}_{8} \mathrm{Nb}_{6} \mathrm{O}_{19} \cdot n \mathrm{H}_{2} \mathrm{O} .{ }^{42)}$ Similar behavior was also reported by the previous studies using $\mathrm{Nb}_{2} \mathrm{O}_{5}$ as a niobium precursor. ${ }^{33)}$ In much higher $\mathrm{KOH}$ concentration range from 8.0 to $18 \mathrm{~mol} \cdot \mathrm{dm}^{-3}$, white-colored precipitates were collected after centrifugation. Figure 1 shows X-ray diffraction (XRD) patterns of solid particles formed by different initial $\mathrm{KOH}$ concentrations from 8.0 to $18 \mathrm{~mol} \cdot \mathrm{dm}^{-3}$. $\mathrm{KN}$ has three-types of polymorphism with orthorhombic, tetragonal, and cubic crystal structures above room temperature. As indexed in Fig. 1(f), split peaks assigned with 011 and 100 as well as 220 and 002 , characteristic of the intensity ratios of an orthorhombic phase, are observed for all samples, and all diffraction peaks shown in Fig. 1(a)-(f) can be perfectly assigned as formation of a $\mathrm{KN}$ phase with the orthorhombic crystal structure (JCPDS No. 00-032-0822) in a single phase. The KN peaks are sharpened by increase in the initial $\mathrm{KOH}$ concentrations from 8 to $14 \mathrm{~mol} \cdot \mathrm{dm}^{-3}$ as shown in Fig. 1(a)(d). Further increase of the $\mathrm{KOH}$ concentration effects peak broading as shown in Fig. 1(f). The crystallite sizes of the $\mathrm{KN}$ particles obtained using 8.0 and $14 \mathrm{~mol} \cdot \mathrm{dm}^{-3} \mathrm{KOH}$ were calculated as 40 and $62 \mathrm{~nm}$, respectively, from Scherrer's equation. The crystallite sizes were increased by the increasing $\mathrm{KOH}$ concentration from 8.0 to $14 \mathrm{~mol} \cdot \mathrm{dm}^{-3}$. 


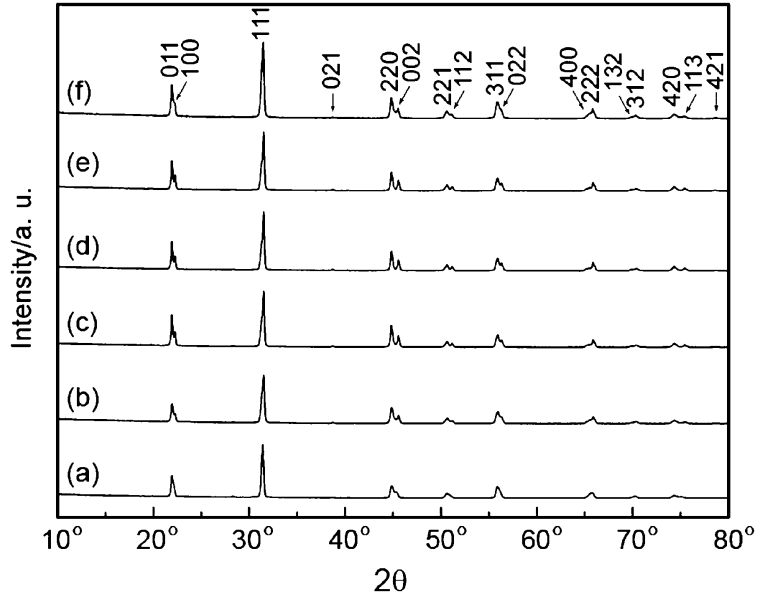

Fig. 1 XRD patterns of $\mathrm{KNbO}_{3}$ fine particles hydrothermally prepared by changing the initial $\mathrm{KOH}$ concentrations: (a) 8.0 ; (b) 10 ; (c) 12 ; (d) 14 ; (e) 16 ; (f) $18 \mathrm{~mol} \cdot \mathrm{dm}^{-3}$. The reaction was carried out by aging at $100^{\circ} \mathrm{C}$ for $24 \mathrm{~h}$ followed by heating at $250^{\circ} \mathrm{C}$ for $3 \mathrm{~h}$ in a Teflon-lined autoclave.

Further increasing $\mathrm{KOH}$ concentration from 14 to 18 $\mathrm{mol} \cdot \mathrm{dm}^{-3}$ results in the decreasing the crystallite sizes from 62 to $28 \mathrm{~nm}$. The apparent yield of $\mathrm{KN}$ was estimated by weighing powders collected away with centrifugation. The yields in the $\mathrm{KOH}$ concentration of 8.0 and $10 \mathrm{~mol} \cdot \mathrm{dm}^{-3}$ were 45 and $89 \%$, respectively. Further increase in the initial $\mathrm{KOH}$ concentrations afforded the desired $\mathrm{KN}$ powders in quantitative yields. These results indicated that $\mathrm{KN}$ fine particles were successfully obtained in the concentrated $\mathrm{KOH}$ aqueous solution under mild conditions starting from soluble $\mathrm{NbCl}_{5}$ precursor solution.

Figure 2 shows FE-SEM images of as-prepared particles, and morphology and particle mean size of the resulting particles are basically changed by the initial $\mathrm{KOH}$ concentrations. Namely, aggregated particles with some octahedralshaped surfaces are formed in the system using $8.0 \mathrm{~mol} \cdot \mathrm{dm}^{-3}$ $\mathrm{KOH}$ (Fig. 2(a)). Further increase in $\mathrm{KOH}$ concentration resulted in formation of irregular-shaped $\mathrm{KN}$ particles with cubical edges as indicated in Fig. 2(b) and (c). In contrast, basically cubic-shaped $\mathrm{KN}$ particles with some cracked surfaces are obtained in the $\mathrm{KOH}$ concentration range from 10 to $18 \mathrm{~mol} \cdot \mathrm{dm}^{-3}$ as shown in Fig. 2(d)-(f). The edges of the particle surfaces become sharpen by the increasing the $\mathrm{KOH}$ concentration from 10 to $18 \mathrm{~mol} \cdot \mathrm{dm}^{-3}$ (Fig. 2(b)-(f)). The mean sizes with a size distribution of $\mathrm{KN}$ particles at different $\mathrm{KOH}$ concentration were $7.0 \pm 3.6 \mu \mathrm{m}(8.0$ $\left.\mathrm{mol} \cdot \mathrm{dm}^{-3}\right), 1.8 \pm 0.8 \mu \mathrm{m}\left(10 \mathrm{~mol} \cdot \mathrm{dm}^{-3}\right), 1.5 \pm 1.0 \mu \mathrm{m}(12$ $\left.\mathrm{mol} \cdot \mathrm{dm}^{-3}\right), \quad 0.9 \pm 0.4 \mu \mathrm{m} \quad\left(14 \mathrm{~mol} \cdot \mathrm{dm}^{-3}\right), \quad 1.0 \pm 0.4 \mu \mathrm{m}$ $\left(16 \mathrm{~mol} \cdot \mathrm{dm}^{-3}\right)$, and $1.3 \pm 0.6 \mu \mathrm{m}\left(18 \mathrm{~mol} \cdot \mathrm{dm}^{-3}\right)$. The particle mean sizes are decreased by the increasing initial $\mathrm{KOH}$ concentrations from 8.0 to $14 \mathrm{~mol} \cdot \mathrm{dm}^{-3}$, and the distribution become narrow by the increasing $\mathrm{KOH}$ concentrations. This behaviour is derived from homogeneous nucleation and enhancement of generation number of $\mathrm{KN}$ growing nuclei by the increasing $\mathrm{KOH}$ concentrations. In any case, the particle mean size was much larger than the crystallite size calculated from XRD pattern so that as-prepared particles were polycrystalline.
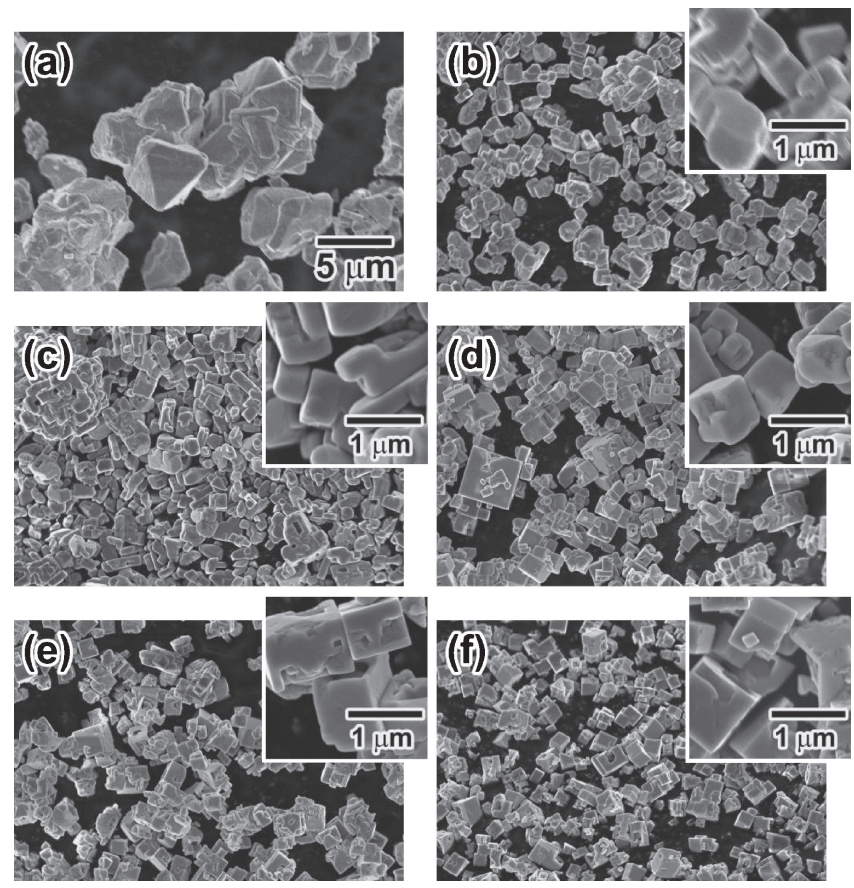

Fig. 2 FE-SEM images of $\mathrm{KNbO}_{3}$ fine particles obtained by the change of the initial $\mathrm{KOH}$ concentration: (a) 8.0 ; (b) 10 ; (c) 12 ; (d) 14 ; (e) 16 ; (f) $18 \mathrm{~mol} \cdot \mathrm{dm}^{-3}$. The scale bar in (a) is common for images. The insets are close-up photos of each image.

\subsection{Effect of two-step aging on $\mathrm{KN}$ particle formation}

Figure 3 exhibits FE-SEM images of KN fine particles obtained by changing two-step aging procedure. Here, the $\mathrm{KOH}$ concentration was fixed at $18 \mathrm{~mol} \cdot \mathrm{dm}^{-3}$. Temperature of the first aging period was adjusted to $100^{\circ} \mathrm{C}$, and period of the second aging with different temperature was fixed to $3 \mathrm{~h}$. XRD measurement indicated that $\mathrm{KN}$ with an orthorhombic morphology were formed as a single phase in all cases. Figure 3(a)-(d) shows KN particles with the second aging temperature at $150^{\circ} \mathrm{C}$ by changing the 1 st aging period from 0 to $72 \mathrm{~h}$. Highly coagulated $\mathrm{KN}$ particles are formed in the absence of the 1st aging as exhibited in Fig. 3(a). In contrast, cubic-shaped KN nanoparticles with sharp edges are obtained by the introduction of the 1st aging. The mean sizes with a size distribution of $\mathrm{KN}$ nanoparticles at different 1 st aging periods are $0.46 \pm 0.26 \mu \mathrm{m}(0 \mathrm{~h}), 0.53 \pm 0.16 \mu \mathrm{m}(24 \mathrm{~h})$, $0.68 \pm 0.28 \mu \mathrm{m}(48 \mathrm{~h})$, and $0.81 \pm 0.42 \mu \mathrm{m}(72 \mathrm{~h}) . \mathrm{KN}$ fine particle of cubic shape with narrow size distribution is obtained when the 1 st aging period is fixed for $24 \mathrm{~h}$ (Fig. 1(b)). When the 1st aging period is prolonged, the particle mean sizes are increased from 0.46 to $0.81 \mu \mathrm{m}$. In the 1st aging, not only KN nuclei formation but also particle growth simultaneously occurred. Actually, apparent yields of $\mathrm{KN}$ particles second-aged at $150^{\circ} \mathrm{C}$ were about only $2-10 \%$, and the yield was increased by depending the aging period. This means that particle growth at $150^{\circ} \mathrm{C}$ was not finished among present aging period. Since the second aging temperature was increased to $200^{\circ} \mathrm{C}$ (Fig. 3(e)-(h)), particle mean sizes were drastically increased and basically cubic-shaped $\mathrm{KN}$ particles with several micron meters are obtained in quantitative yields. The particle surfaces seemed to become somewhat flat and smooth by the introduction of the first 


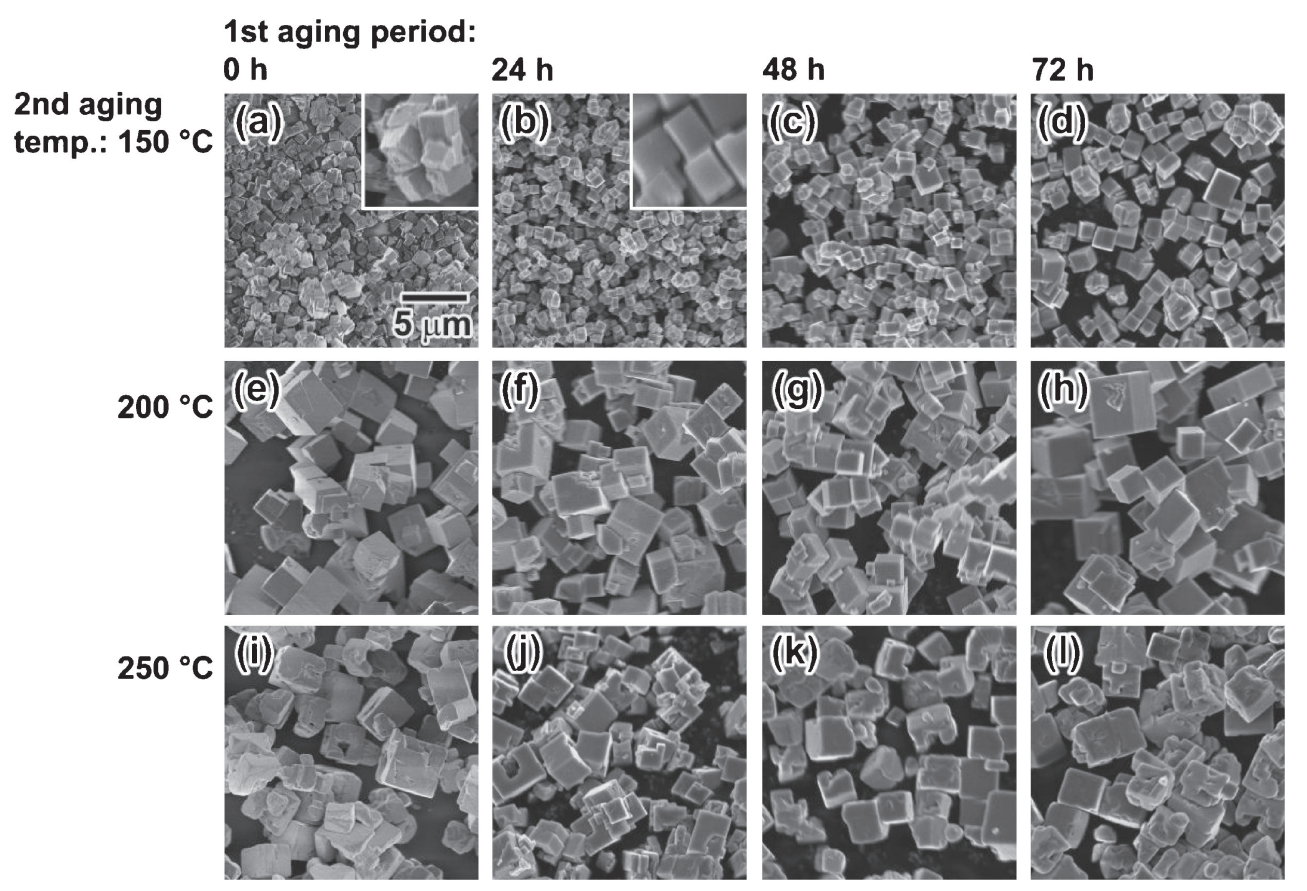

Fig. 3 Effect of aging conditions for the synthesis of $\mathrm{KNbO}_{3}$ fine particles. The 1 st aging periods for (a), (e), and (i): $0 \mathrm{~h}$; for (b), (f), and (j): $24 \mathrm{~h}$; for (c), (g), and (k): $48 \mathrm{~h}$; for (d), (h), and (1): $72 \mathrm{~h}$. The 2nd aging temperature of (a)-(d), (e)-(h), and (i)-(l) were 150, 200, and $250^{\circ} \mathrm{C}$, respectively.

aging (see: insets of Fig. 3(e) and (f)). Further prolongation of the first aging leads some coagulation and increase in the particle mean size. The second aging temperature was further increased to $250^{\circ} \mathrm{C}$. FE-SEM images of the resulting $\mathrm{KN}$ particles are exhibited in Fig. 3(i)-(j). Also at this aging temperature, $\mathrm{KN}$ particles are formed in quantitatively, $\mathrm{KN}$ fine particles with flat and smooth surfaces are obtained by the two-step aging. The KN shown in Fig. 3(j) is the particle with smallest particle mean size among the particles exhibited in Fig. 3(e)-(f) forming KN quantitatively. In this regard, the optimized condition to obtain cubic-shaped $\mathrm{KN}$ fine particle can be set as follows: the first aging at $100^{\circ} \mathrm{C}$ for $24 \mathrm{~h}$ followed by aging at $250^{\circ} \mathrm{C}$ for $3 \mathrm{~h}$. One plausible reason why the increase in particle mean sizes by prolonged 1 st aging period is the decreasing in $\mathrm{KN}$ nuclei number by tremendous aggregation and/or the Ostwald ripening between them.

\subsection{Preparation of $\mathrm{NN}$ fine particles: Effects of $\mathrm{NaOH}$ concentration}

In spite of $\mathrm{NN}$ of an antiferroelectric material at room temperature, $\mathrm{NN}$ forms a solid solution with $\mathrm{KN}$ to show ferroelectricity. ${ }^{44,45)}$ In this regard, the present two-step aging system for $\mathrm{KN}$ synthesis mentioned above can be applied to $\mathrm{NN}$ fine particle synthesis with using $\mathrm{NaOH}$. The aging condition was fixed at $100^{\circ} \mathrm{C}$ for $24 \mathrm{~h}$ followed by $250^{\circ} \mathrm{C}$ for 3 h. Figures 4 and 5 show XRD patterns and FE-SEM images of solid particles obtained by changing initial $\mathrm{NaOH}$ concentrations from 2.0 to $20 \mathrm{~mol} \cdot \mathrm{dm}^{-3}$. When the initial concentration is adjusted to $2.0 \mathrm{~mol} \cdot \mathrm{dm}^{-3}$, the formation of NN was confirmed with the presence of undefined solid phases as shown in Fig. 4(a). Cubic-shaped particles with pores on the planes in Fig. 5(a), can be identified as NN particles, but and some fibrous solids was still undefined.

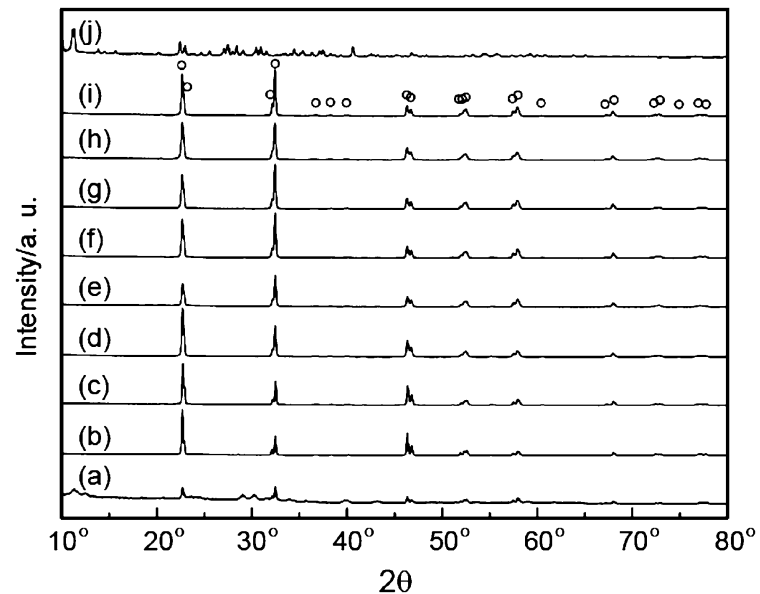

Fig. 4 XRD profiles of NN fine particles obtained by changing the initial $\mathrm{NaOH}$ concentration: (a) 2.0; (b) 4.0; (c) 6.0; (d) 8.0; (e) 10; (f) 12; (g) 14; (h) 16 ; (i) 18 ; (j) $20 \mathrm{~mol} \cdot \mathrm{dm}^{-3}$. Preparation was carried out by aging at $100^{\circ} \mathrm{C}$ for $24 \mathrm{~h}$ followed by heating at $250^{\circ} \mathrm{C}$ for $3 \mathrm{~h}$ in a Teflon-lined autoclave. Peaks with circle mark in Fig. 4(i) are the representative peaks assigned as orthorhombic NN.

Further increasing initial $\mathrm{NaOH}$ concentration in the rage from 4.0 to $18 \mathrm{~mol} \cdot \mathrm{dm}^{-3}$ affords formation of $\mathrm{NN}$ phase with an orthorhombic crystal structure as a single phase as shown in Fig. 4(b)-(i). Circle marks in Fig. 4(i) are the representative peaks assigned as the orthorhombic NN (JCPDS No. 00033-1270). Among this $\mathrm{NaOH}$ concentration range, the NN particles were obtained in quantitative yields. FE-SEM images exhibited in Fig. 5(b)-(i) indicate that $\mathrm{NN}$ fine particles with basically cubic morphology are fabricated among this $\mathrm{NaOH}$ concentration range. Also in this case, 1st aging at $100^{\circ} \mathrm{C}$ for $24 \mathrm{~h}$ played an important rule to obtain NN particles with smooth surfaces. In contrast, solid phase 

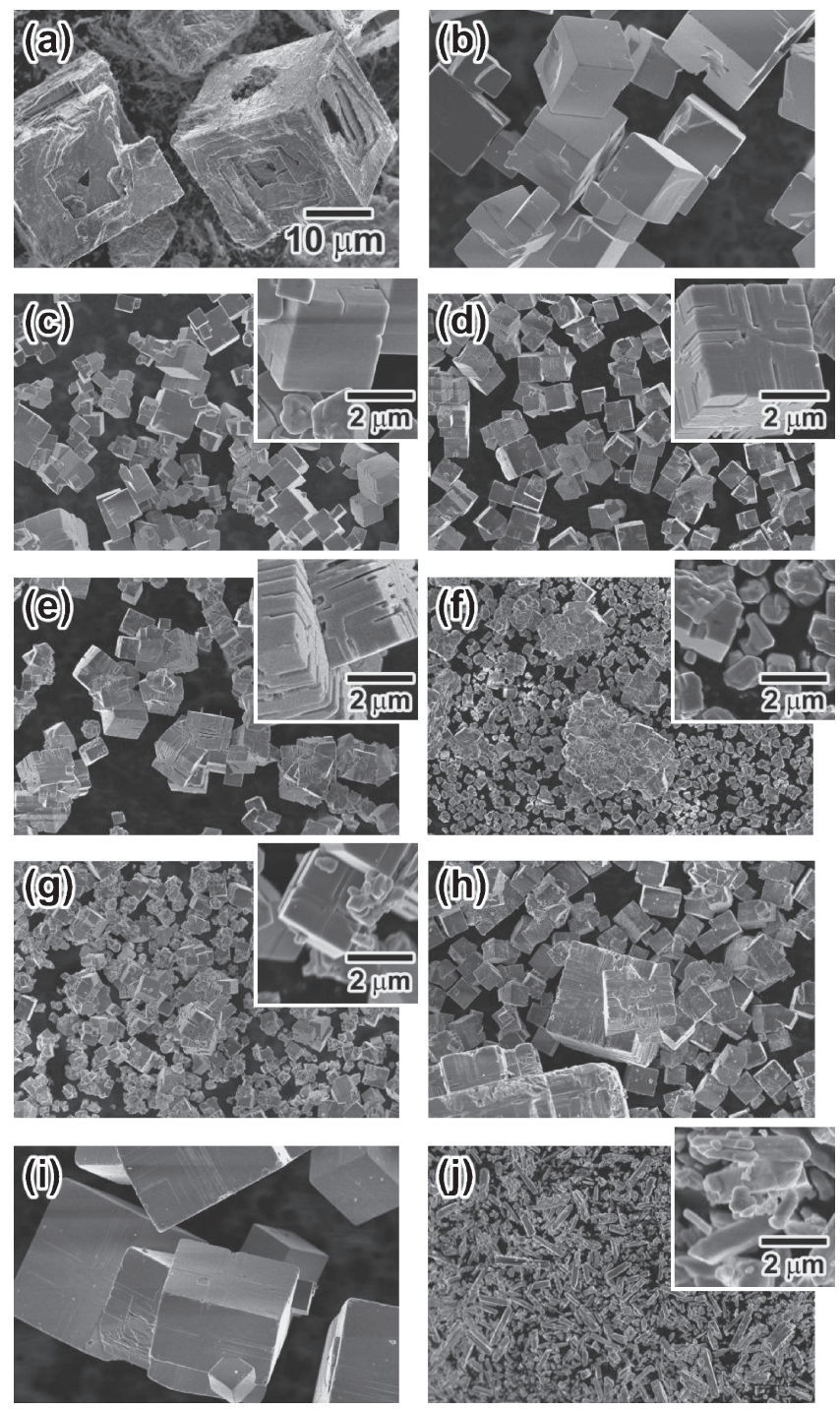

Fig. 5 FE-SEM images of NN fine particles obtained by the change of the initial $\mathrm{NaOH}$ concentration: (a) 2.0 ; (b) 4.0 ; (c) 6.0 ; (d) 8.0 ; (e) 10 ; (f) 12 ; (g) 14; (h) 16; (i) 18 ; (j) $20 \mathrm{~mol} \cdot \mathrm{dm}^{-3}$. The scale bar in (a) is common for images. The insets are close-up SEM photographs of each image.

can be assigned as sodium hexaniobates, $\mathrm{Na}_{8-x}\left(\mathrm{H}_{3} \mathrm{O}\right)_{x^{-}}$ $\mathrm{Nb}_{6} \mathrm{O}_{19} \cdot n \mathrm{H}_{2} \mathrm{O}$, ${ }^{46}$ ) (see $\mathrm{Na}_{8} \mathrm{Nb}_{6} \mathrm{O}_{19} \cdot 13 \mathrm{H}_{2} \mathrm{O}$ : JCPDS No. 00014-0370) with a rod-like morphology is formed as a most plausible phase in $20 \mathrm{~mol} \cdot \mathrm{dm}^{-3} \mathrm{NaOH}$ (Figs. 4(j) and 5(j)). In the case of the $\mathrm{KN}$ synthesis, corresponding potassium hexaniobate was formed as a soluble intermediate. However, for the NN synthesis, sodium hexaniobates was precipitated by its low solubility in highly concentrated $\mathrm{NaOH}$ solution. ${ }^{33,46)}$ As shown in Fig. 4(a)-(f), the NN particle mean sizes are once decreased from ca. 20 to $1.0 \mu \mathrm{m}$ by the increasing initial $\mathrm{NaOH}$ concentration from 2.0 to $12 \mathrm{~mol} \cdot \mathrm{dm}^{-3}$. Further increasing $\mathrm{NaOH}$ concentration brings the increasing particle mean sizes (Fig. 4(f)-(i)). This behavior could be explained by the formation of sodium hexaniobates with low solubility. Namely, increase in $\mathrm{NaOH}$ concentration resulted in enhancement of nucleation number of $\mathrm{NN}$ producing much smaller $\mathrm{NN}$ particles. Further increase of the $\mathrm{NaOH}$ concentration enhanced the formation of sodium hexaniobates, which leading to decrease of the
Table 1 Piezoelectric properties of ceramics prepared by using hydrothermally prepared $\mathrm{KN}$ and $\mathrm{NN}$ fine particles. The sintering period was adjusted to $2 \mathrm{~h}$.

\begin{tabular}{lccccc}
\hline Sample & Sint. temp. $\left({ }^{\circ} \mathrm{C}\right)$ & $\rho\left(\mathrm{g} / \mathrm{cm}^{3}\right)$ & $\varepsilon_{33}^{\mathrm{T}} / \varepsilon_{0}$ & $k_{\mathrm{p}}(\%)$ & $d_{33}(\mathrm{pC} / \mathrm{N})$ \\
\hline KN1 $^{* 1}$ & 1,020 & 4.05 & 877 & 25.5 & 133.4 \\
KN2 $^{* 1}$ & 1,040 & 4.07 & 875 & 27.2 & 120.0 \\
KN3 $^{* 1}$ & 1,060 & 3.76 & 727 & 21.4 & 83.7 \\
\hline NKN1 $^{* 2}$ & 1,020 & 4.00 & 569 & 28.9 & 100.1 \\
NKN2 $^{* 2}$ & 1,040 & 4.05 & 530 & 23.1 & 89.2 \\
NKN3 $^{* 2}$ & 1,060 & 3.86 & 435 & 21.7 & 78.5 \\
\hline
\end{tabular}

${ }^{* 1}$ Cubic-shaped $\mathrm{KN}$ fine particles shown in Fig. 2(f) were used; ${ }^{* 2} \mathrm{~A}$ mechanically mixed powder of KN exhibited in Fig. 2(f) and Cubicshaped NN fine particles exhibited in Fig. 5(c) was used of the preparation. The mixing ratio of $\mathrm{KN} / \mathrm{NN}$ was $1 / 1$ (mass $/$ mass).

$\rho$ : density; $\varepsilon_{33}^{\mathrm{T}} / \varepsilon_{0}$ : dielectric constant; $k_{\mathrm{p}}$ : coupling factor; $d_{33}$ : piezoelectric constant

direct precursor concentration for the nucleation of $\mathrm{NN}$ in the solution. As a result, the particle mean sizes are increased again as exhibited in Fig. 4(i). Such behavior was not observed for the present $\mathrm{KN}$ synthesis forming $\mathrm{K}_{8} \mathrm{Nb}_{6}-$ $\mathrm{O}_{19} \cdot n \mathrm{H}_{2} \mathrm{O}$ as a soluble precursor. This result also supported that precipitation of sodium hexaniobates played important rule for the change of the particle mean size. In this regard, size of cubic-shaped $\mathrm{NN}$ fine particles are readily controlled by change in the initial $\mathrm{NaOH}$ concentration in the present two-step aging hydrothermal reaction, and well-crystallized $\mathrm{NN}$ fine particles were also formed under mild conditions.

\subsection{Piezoelectric property of hydrothermally prepared KN and NKN ceramics}

Piezoelectric properties of KN- and NKN-based ceramics were evaluated, where the samples were prepared with $\mathrm{KN}$ and NN fine particles obtained in the present study. KN ceramics were prepared from the cubic-shaped $\mathrm{KN}$ fine particles shown in Fig. 2(f), and NKN ceramics from the same weight mixture of $\mathrm{KN}$ and $\mathrm{NN}$ fine particles shown in Fig. 2(f) and Fig. 5(c). As prepared ceramics with different sintering temperatures are abbreviated as KN1-3 and NKN1-3. As a result of the comparison of piezoelectric properties such as dielectric constant $\left(\varepsilon_{33}{ }^{\mathrm{T}} / \varepsilon_{0}\right)$, coupling factor $\left(k_{\mathrm{p}}\right)$, and piezoelectric constant $\left(d_{33}\right)$ of KN1-3 and NKN1-3 in Table 1, the optimized sintered temperature of the $\mathrm{KN}$ and NKN ceramics was $1,020^{\circ} \mathrm{C}$ because $d_{33}$ was reached in maximum to 133.4 and 100.1, respectively. Densities $(\rho)$ of the KN and NKN ceramics were reached to 4.07 and $4.05 \mathrm{~g} / \mathrm{cm}^{3}$, respectively, at $1,040^{\circ} \mathrm{C}$. Further increase in the sintering temperature resulted in the decrease in the densities, possibly because of the volatilization of potassium oxide. The theoretical density of $\mathrm{KN}$ is 4.62 $\mathrm{g} / \mathrm{cm}^{3}$, the lowered $\delta$ of the resulting ceramics is due to the existence of the pores in the ceramics. Actually, some pores are seen in the FE-SEM images of KN1 and NKN1 as shown in Fig. 6(a) and (b). The resulting grain diameters of KN1 and NKN1 were calculated as 1.5 and $5 \mu \mathrm{m}$, respectively. Taking the particle mean size of the $\mathrm{KN}$ particles, $1.3 \mu \mathrm{m}$, into the consideration, the hydrothermally prepared $\mathrm{KN}$ particles indicated good sintering property keeping the original particle morphology and size. In contrast, the 

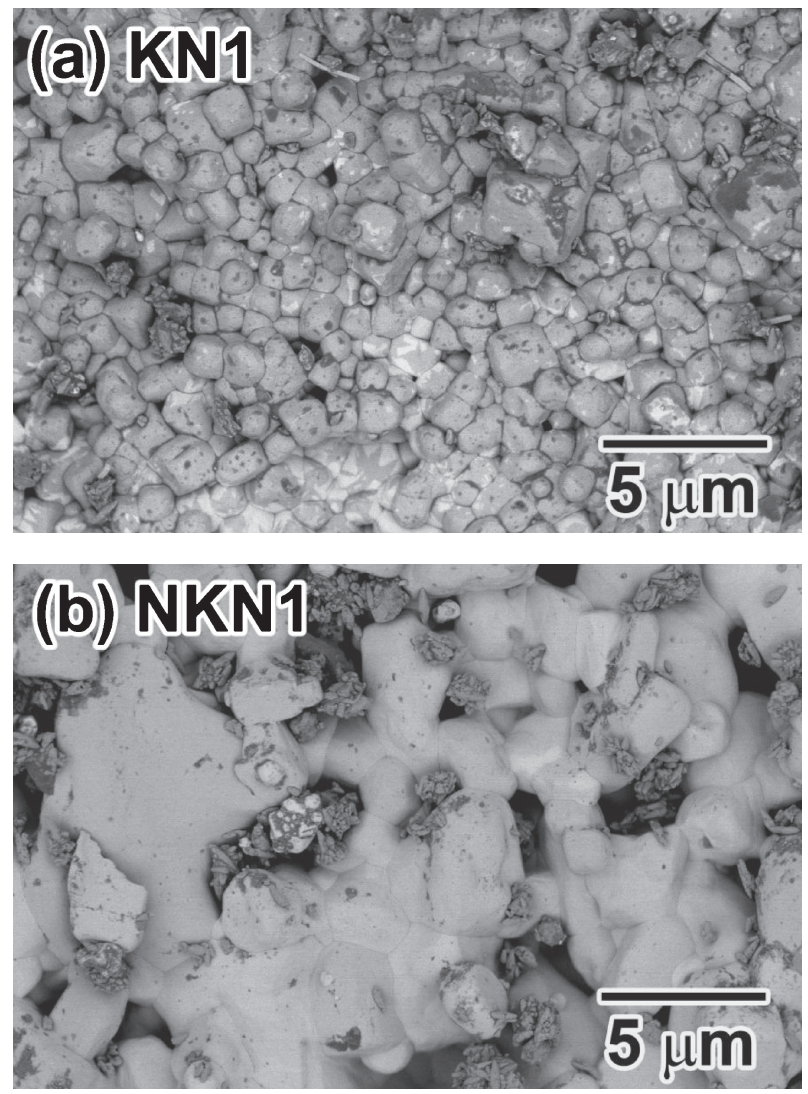

Fig. 6 FE-SEM photographs of hydrothermally prepared $\mathrm{KN}$ and NKN ceramics KN1 and NKN1 sintered at $1,020^{\circ} \mathrm{C}$ for $2 \mathrm{~h}$. (a) KN1: KN ceramics obtained by sintering cubic-shaped $\mathrm{KN}$ fine particles shown in Fig. 2(f) at $1,020^{\circ} \mathrm{C}$ for $2 \mathrm{~h}$; (b) NKN1: NKN ceramics prepared by sintering a mixed powder of $\mathrm{KN}$ and $\mathrm{NN}$ exhibited in Fig. 2(f) and Fig. 5(c), respectively. The mixing ratio of $\mathrm{KN} / \mathrm{NN}$ was fixed at $1 / 1$ (mass/mass).

domain growth by the sintering was observed for NKN1 at the same sintering condition. Relatively lower $d_{33}$ value of NKN1 than KN1 might be due to difference in the grain size of the resulting ceramics. Actually, $\varepsilon_{33}$ of KN1-3 is much higher than that of NKN1-3. These results suggested that simple mixing KN with $\mathrm{NN}$ was not effective to obtain high performance NKN ceramics because of the difficulty in the grain growth by the sintering. Detailed investigations on effect of particle morphology, sintering conditions, doping etc. are now in progress for the development of lead-free piezoelectric materials with high performance.

\section{Conclusions}

We have prepared $\mathrm{KN}$ and NN fine particles with cubicshape controlling with size by a hydrothermal method starting from a soluble $\mathrm{NbCl}_{5}$ aqueous solution. Main concluding remarks obtained this work are as follows:

(1) Cubic-shaped KN and NN fine particles with orthorhombic crystal structures were prepared in a single phase starting from a soluble $\mathrm{NbCl}_{5}$ aqueous solution and alkaline metal hydroxide aqueous solutions by a highly condensed hydrothermal method. The particle mean sizes were readily controlled by changing the initial $\mathrm{KOH}$ and $\mathrm{NaOH}$ concentrations.
(2) $\mathrm{KN}$ and $\mathrm{NKN}$ fine ceramics were readily obtained by sintering of hydrothermally prepared $\mathrm{KN}$ and $\mathrm{NN}$ fine particles. KN exhibited good sintering property keeping with the original particle size and shape.

\section{Acknowledgements}

The authors greatly appreciate Ms. M. Matsuda, Ms. N. Nakagawa, Ms. M. Takahashi, and Ms. T. Ishikawa for the synthesis of NN and KN particles. This work was financially supported by NEDO Nanotech Challenge Project.

\section{REFERENCES}

1) Z.-G. Ye (ed.): Handbook of advanced dielectric, piezoelectric and ferroelectric materials: Synthesis, properties and application, (Woodhead Publishing Limited, 2008).

2) Y. Saito, H. Takao, T. Tani, T. Nonoyama, K. Takatori, T. Homma, T. Nagaya and M. Nakamura: Nature 432 (2004) 84-87.

3) M. Nyman, F. Bonhomme, T. M. Alam, M. A. Rodriguez, B. R. Cherry, J. L. Krumhansl, T. M. Nenoff and A. M. Sattler: Science 297 (2002) 996-998.

4) K. Domen, A. Kudo, M. Shibata, A. Tanaka, K. Maruya and T. Onishi: J. Chem. Soc. Chem. Commun. 1986 (1986) 1706-1707.

5) Q.-P. Ding, Y.-P. Yuan, X. Xiong, R.-P. Li, H.-B. Huang, Z.-S. Li, T. Yu, Z.-G. Zou and S. G. Yang: J. Phys. Chem. C 112 (2008) 1884618848.

6) H. Nagata, K. Matsumoto, T. Hirosue, Y. Hiruma and T. Takenaka: Jpn. J. Appl. Phys. 46 (2007) 7084-7088.

7) C.-H. Wang and J.-J. Wang: Jpn. J. Appl. Phys. 48 (2009) 041403.

8) H. Hayashi, Y. Hakuta and Y. Kurata: J. Mater. Chem. 14 (2004) 20462051.

9) V. Lingwal and N. S. Panwar: Ferroelectrics 300 (2004) 3-14.

10) R. Zuo, J. Rödel, R. Chen and L. Li: J. Am. Ceram. Soc. 89 (2006) 2010-2015.

11) K. Uchino: Ferroelectric Devices, (Marcel Dekker, New York, 2000) pp. 275-303.

12) K. M. Nair (ed.): Proc. of the High Strain Piezoelectric Materials, Devices and Applications, and Advanced Dielectric Materials and Multilayer Electric Devices Symposia, (Westerville, Ohio, American Ceramic Society, 2004) pp. 253-263.

13) D. C. Lupascu and J. Rödel: Adv. Eng. Mater. 7 (2005) 882-898.

14) M. Wicks: UK Ministry of Trade and Industry, The Stationery Office Limited, (2006).

15) Y. Saito and H. Takao: J. Eur. Ceram. Soc. 27 (2007) 4085-4092.

16) U. Flückiger and H. Arend: J. Cryst. Growth 43 (1978) 406-416.

17) T. Sugimoto: Monodispersed Particles, (Elsevier, Amsterdam, 2001) pp. 187-452.

18) Y. Waseda and A. Muramatsu (eds.): Morphology Control of Materials and Nanoparticles, (Springer, Berlin, 2003) pp. 25-62.

19) J. A. Horn, S. C. Zhang, U. Selvaraj, G. L. Messing and S. TrolierMcKinstry: J. Am. Ceram. Soc. 82 (1999) 921-926.

20) T. Tani: J. Korean Phys. Soc. 32 (1998) S1217-1220.

21) K. Kanie, H. Sakai, J. Tani, H. Takahashi and A. Muramatsu: Mater. Trans. 48 (2007) 2174-2178.

22) K. Kanie, Y. Numamoto, S. Tsukamoto, T. Sasaki, M. Nakaya, J. Tani, H. Takahashi and A. Muramatsu: Mater. Trans. 52 (2011) 1396-1401.

23) T. Sugimoto, K. Sakata and A. Muramatsu: J. Colloid Interf. Sci. 159 (1993) 372-382.

24) T. Sugimoto and K. Sakata: J. Colloid Interf. Sci. 152 (1992) 587-590.

25) T. Sugimoto, M. M. Khan and A. Muramatsu: Colloid Surf. A 70 (1993) 167-169.

26) T. Sugimoto, S. Waki, H. Itoh and A. Muramatsu: Colloid Surf. A 109 (1996) 155-165.

27) K. Kanie and T. Sugimoto: Chem. Commun. 2004 (2004) 1584-1585.

28) T. Sugimoto, X. Zhou and A. Muramatsu: J. Colloid Interf. Sci. 252 (2002) 339-346.

29) T. Sugimoto, X. Zhou and A. Muramatsu: J. Colloid Interf. Sci. 259 (2003) 53-61. 
30) J. Cuya, N. Sato, K. Yamamoto, H. Takahashi and A. Muramatsu: High Temp. Mat. Proc. 22 (2003) 197-201.

31) C.-H. Lu, S.-Y. Lo and H.-C. Lin: Mater. Lett. 34 (1998) 172-176.

32) G. Wang, Y. Yu, T. Grande and M.-A. Einarsrud: J. Nanosci. Nanotechnol. 9 (2009) 1465-1469.

33) G. K. L. Goh, F. F. Lange, S. M. Haile and C. G. Levi: J. Mater. Res. 18 (2003) 338-345

34) N. Kumada, T. Kyoda, Y. Yonesaki, T. Takei and N. Kinomura: Mater. Res. Bull. 42 (2007) 1856-1862.

35) D. R. Modeshia, R. J. Darton, S. E. Ashbrook and R. I. Walton: Chem. Commun. 2009 (2009) 68-70.

36) A. D. Handoco and G. K. L. Goh: Green Chem. 12 (2010) 680-687.

37) C. Sun, X. Xing, J. Chen, J. Deng, L. Li, R. Yu, L. Qiao and G. Liu: Eur. J. Inorg. Chem. 2007 (2007) 1884-1888.

38) F. Zhang, L. Han, S. Bai, T. Sun, T. Karaki and M. Adachi: Jpn. J. Appl. Phys. 47 (2008) 7685-7688.

39) T. Maeda, N. Takiguchi, T. Morita, M. Ishikawa and T. Hemsel:
J. Korean Phys. Soc. 57 (2010) 924-928.

40) T. Maeda, N. Takiguchi, M. Ishikawa, T. Hemsel and T. Morita: Mater. Lett. 64 (2010) 125-128.

41) K. Kanie, H. Mizutani, A. Terabe, Y. Numamoto, S. Tsukamoto, H. Takahashi, M. Nakaya, J. Tani and A. Muramatsu: Jpn. J. Appl. Phys. in press.

42) H.-M. Zhou, D.-Q. Yi, Y. Zhang and S.-1. Zheng: Hydrometallurgy 80 (2005) 126-131.

43) J.-P. Jolivet, C. Chanéac and E. Tronc: Chem. Commun. 2004 (2004) 481-482.

44) X. Wang, U. Helmersson, S. Olafsson, S. Rudner, L.-D. Wernluand and S. Gevorgian: Appl. Phys. Lett. 73 (1998) 927-929.

45) C.-R. Cho, J.-H. Koh, A. Grishin, S. Abadei and S. Gevorgian: Appl. Phys. Lett. 76 (2000) 1761-1763.

46) H. Zhu, Z. Zheng, X. Gao, Y. Huang, Z. Yan, J. Zou, H. Yin, Q. Zou, S. H. Kable, J. Zhao, Y. Xi, W. N. Martens and R. L. Frost: J. Am. Chem. Soc. 128 (2006) 2373-2384. 